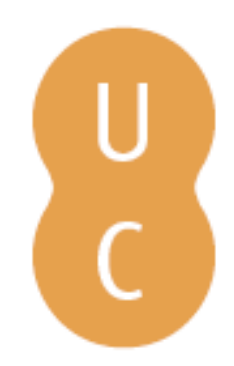

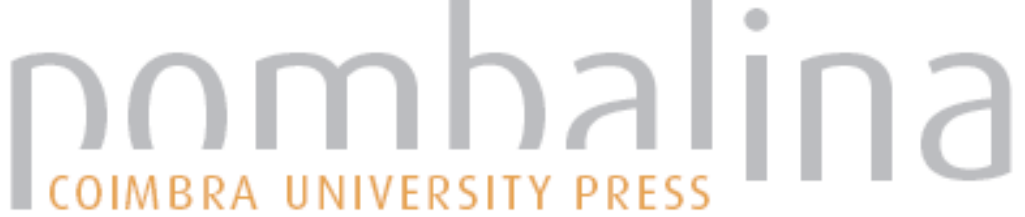

\section{Manipulação de constrangimentos no ténis}

Autor(es): $\quad$ Carvalho, Adriano; Carvalho, João; Araújo, Duarte

Publicado por: Imprensa da Universidade de Coimbra

URL

persistente: URI:http://hdl.handle.net/10316.2/41769

DOI: $\quad$ DOl:https://doi.org/10.14195/978-989-26-1286-7_8

Accessed : $\quad$ 26-Apr-2023 15:15:55

A navegação consulta e descarregamento dos títulos inseridos nas Bibliotecas Digitais UC Digitalis, UC Pombalina e UC Impactum, pressupõem a aceitação plena e sem reservas dos Termos e Condições de Uso destas Bibliotecas Digitais, disponíveis em https://digitalis.uc.pt/pt-pt/termos.

Conforme exposto nos referidos Termos e Condições de Uso, o descarregamento de títulos de acesso restrito requer uma licença válida de autorização devendo o utilizador aceder ao(s) documento(s) a partir de um endereço de IP da instituição detentora da supramencionada licença.

Ao utilizador é apenas permitido o descarregamento para uso pessoal, pelo que o emprego do(s) título(s) descarregado(s) para outro fim, designadamente comercial, carece de autorização do respetivo autor ou editor da obra.

Na medida em que todas as obras da UC Digitalis se encontram protegidas pelo Código do Direito de Autor e Direitos Conexos e demais legislação aplicável, toda a cópia, parcial ou total, deste documento, nos casos em que é legalmente admitida, deverá conter ou fazer-se acompanhar por este aviso. 
IMPRENSA DA UNIVERSIDADE DE COIMBRA

COIMBRA UNIVERSITY PRESS

RAUL A.

MARTINS

GONÇALO DIAS

PEDRO CABRAL MENDES

\section{EDITORES}

ESTRATÉGIA

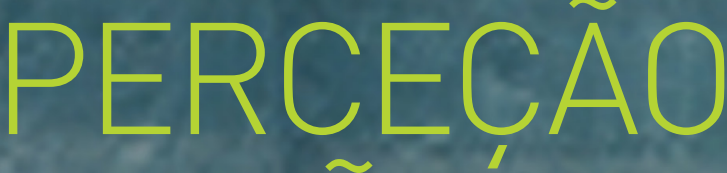

EAGÃA

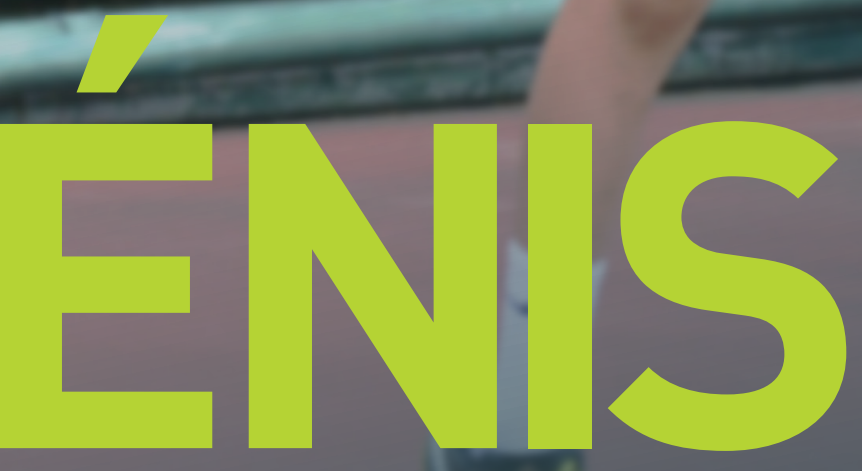




\section{CA P ÍTULO 8}

\section{MANIPULAÇÃO DE CONSTRANGIMENTOS NO TÉNIS}

Adriano Carvalbo

João Carvalbo

Duarte Araújo

\section{Introdução}

O estudo e compreensão dos processos de aprendizagem desportiva têm sido dominados pela corrente clássica cognitivista (Passos e col., 2006). Esta corrente teórica, assente nos princípios do processamento de informação, considera que para existir uma tomada de decisão e consequente ação é necessário haver um estímulo prévio, captado pelos órgãos sensoriais e comparado com as representações mentais já existentes na memória do executante. Segundo esta teoria, a organização de uma ação motora, dirigida para um determinado objetivo, está dependente de uma relação estímulo/resposta já construída e armazenada na memória (Carvalho e col., 2011; Davids e col., 2012). Desta forma, o fortalecimento das representações mentais do atleta irá conduzir a uma modificação permanente do comportamento motor.

Como consequência desta visão do comportamento desportivo, desenvolveram-se modelos de treino que assentam na redução da incerteza das ações e na internalização dos processos de tomada de decisão durante o treino (ver discussões em Carvalho e col., 2011; 
Davids e col., 2013; Seifert e col., 2013). Assim, a apresentação de um modelo "ideal" de execução motora (muitas vezes demonstrado por um expert), com componentes críticas minuciosamente descritas, desempenha um papel fundamental nesta abordagem (Passos e col., 2006), tendo como objetivo o fortalecimento das representações mentais, a partir das quais se desenvolvem capacidades percetivas e motoras. Aqui, a variabilidade e o erro na execução de um determinado gesto técnico são vistos como ruído, devendo ser eliminados ou reduzidos para que o gesto se aproxime da execução de uma norma ou modelo utilizado (Davids e col., 2003). Baseando-se no paradigma acima descrito, a metodologia de treino tem características tais como:

a) Exercícios centrados na execução de habilidades motoras que tendam a isolar as ações do contexto competitivo em que estas ocorrem;

b) Treinos maioritariamente centrados na técnica e com uma lista de habilidades motoras ensinadas seq uencialmente;

c) Utilização de métodos de decomposição da tarefa, independentes do contexto de performance;

d) Sobrevalorização do papel da repetição ou do volume de prática no treino de habilidades, como forma de aproximar o gesto técnico ao de um modelo ideal e de fortalecer as representações mentais, tendo como objetivo transferir essas habilidades para o contexto de performance;

e) Utilização da demonstração, instrução e informação de retorno como forma de prescrever ações ótimas a serem executadas pelos jogadores;

f) Avaliação das decisões (ações), após estas serem realizadas pelos jogadores, através da comparação com um modelo "ideal".

Em suma, a metodologia de treino desenvolvida a partir da abordagem cognitivista centra-se na melhoria de aspetos físicos 
e psicológicos dos jogadores sobrevalorizando modelos de treino que separam a ação do contexto de competição e que visam a modelação do comportamento técnico de acordo com um padrão "ideal" de execução.

No entanto, vários estudos (Chow e col., 2007; Davids e col., 2013) mostram que este tipo de métodos, apesar de desenvolverem uma elevada estabilidade técnica na execução de determinados movimentos desportivos, acaba por trazer aos jogadores pouca capacidade para tomar decisões de acordo com as novidades que a competição apresenta, assim como menor capacidade de adaptação ao jogo, uma vez que o jogador treina pouco a interação com um ambiente em mudança. Ou seja, o treino baseia-se na utilização mais ou menos frequente de ações desacopladas do contexto de jogo e definidas de acordo com modelos ótimos de execução que não fornecem as condições necessárias para que, a partir da interação interpessoal (o jogador e o seu opositor), possam emergir decisões e ações de performance funcionais e específicas de cada jogador (Chow e col., 2006; Chow e col., 2007; Davids e col., 2013).

\section{Competições desportivas como sistemas dinâmicos}

Contrastando com a visão atrás descrita, estudos recentes revelam que as competições desportivas podem ser consideradas como sistemas dinâmicos, compostos por diversas partes em constante interação - jogador, opositor, árbitros, público, condições climatéricas, contexto competitivo, motivações pessoais (Chow e col., 2006; Chow e col., 2007). Estes trabalhos mostram que, mesmo os atletas de elite que foram sujeitos a muitos anos de prática, não são capazes de reproduzir padrões de movimento exatamente iguais (Chow e col., 2006). Parece então evidente que a variabilidade e a incerteza são características intrínsecas dos jogos desportivos, surgindo esta variabilidade 
devido aos fatores (constrangimentos) individuais de cada um dos executantes e aos fatores (constrangimentos) ambientais específicos que envolvem cada situação de performance. Assim sendo, pode concluir-se que cada situação desportiva é única e inimitável, uma vez que os constrangimentos individuais e ambientais que moldam a variabilidade de comportamentos são específicos dessa situação e alteram-se ao longo do tempo. Neste sentido, a habilidade desportiva pode ser definida como a capacidade de adaptação intencional à interação de constrangimentos impostos pelo ambiente durante uma determinada situação desportiva.

Esta informação tem implicações importantes para o treino, evidenciando a necessidade de se estudar e compreender a aprendizagem de habilidades desportivas através de princípios teóricos e metodológicos que contemplem a influência dos constrangimentos específicos de cada jogador e a interação destes com os constrangimentos ambientais em que se realiza cada modalidade desportiva (Chow e col., 2006; Chow e col., 2007; Davids e col., 2012; Davids e col., 2013).

\section{Abordagem centrada nos constrangimentos}

A abordagem centrada nos constrangimentos utiliza conceitos e ferramentas dos sistemas dinâmicos para caracterizar a interação entre o indivíduo e o meio envolvente (Chow e col., 2006). Esta relação entre o indivíduo e o meio que o rodeia é expressa por comportamentos autoorganizados, ou seja, que emergem a partir da interação entre os vários constrangimentos que envolvem a performance, sendo que estes dividem-se em três categorias (Newell, 1986):

i) Constrangimentos do indivíduo - Referem-se às características de cada atleta, genéticas e adquiridas, tais como os seus atributos físicos (altura, peso, composição corporal e força 
da conexão de sinapses no cérebro) e as suas características psicológicas (motivações, intenções, cognições e emoções). Um dos constrangimentos do indivíduo que deve ser amplamente considerado é o design neuroanatómico dos músculos e das articulações do corpo humano, uma vez que, para além de ser individualmente diferenciado, este sofre diversas modificações ao longo da idade, o que deve ser tomado em conta no planeamento do treino, consoante as idades dos praticantes. Todas estas características, únicas em cada indivíduo, devem ser vistas como recursos que estes utilizam para cumprirem o objetivo da tarefa que lhes é proposta.

ii) Constrangimentos do ambiente - Podem ser de natureza física (p. ex., vento, luminosidade natural, chuva, altitude) ou de natureza social (p. ex., normas culturais e sociais, pais, treinador, colegas de treino, outros jogadores).

iii) Constrangimentos de tarefa - Estão diretamente ligados à tarefa a desempenhar e têm um papel muito importante na aquisição e desenvolvimento de habilidades, uma vez que incluem as regras do jogo, sistemas de pontuação, dimensão do espaço de jogo, número de jogadores, objetivo do jogo, equipamento usado (p. ex., altura da rede, tipo de bolas, dimensão e peso das raquetes) e objetivos da tarefa (p. ex.., colocação da bola num dado local, número de pontos que é necessário realizar, condições para a realização dos pontos).

A abordagem centrada nos constrangimentos assenta na convicção de que é a partir da interação dos constrangimentos (indivíduo, ambiente e tarefa) que emerge, a partir de processos de autorganização, o comportamento desportivo intencional (Newell, 1986; Newell, 1996). A singularidade de cada um destes constrangimentos em interação (p. ex., cada indivíduo é único; as condições ambientais são muito variáveis; a prestação do adversário nunca é igual) 
leva, naturalmente, à procura de eficácia assente na exploração da variabilidade de soluções motoras como forma de promover a adaptação às características dinâmicas dos constrangimentos existentes na competição (Chow e col., 2006; Seifert e col., 2013). Esta adaptação contínua entre o indivíduo e as condições do ambiente é mais eficaz à medida que o jogador se torna sensível à informação relevante para agir de modo a atingir o objetivo. Ou seja, as fontes de informação disponíveis num determinado contexto competitivo apresentam, de acordo com as capacidades do próprio indivíduo, possibilidades de ação que o atleta pode realizar. Assim sendo, durante a performance, os jogadores afinam a sua perceção às fontes de informação relevantes. Pelo que, o treino, através de exercícios representativos da competição, deve expor os jogadores às fontes de informação que existem na competição desportiva e que são consideradas relevantes para a realização da tarefa (Araújo \& Carvalho, 2007; Chow e col., 2006; Chow e col., 2007; Davids e col., 2013).

Essa abordagem preconiza que a manipulação de constrangimentos chave do indivíduo, do ambiente e da tarefa, é uma ferramenta fundamental para fazer surgir, através de processos de autorganização, o comportamento desportivo dirigido a um determinado objetivo (Chow e col., 2006; Chow e col., 2007). No ténis, por exemplo, quando o treinador quer proporcionar um tipo de batimento capaz de fazer com que a bola passe a rede com uma boa margem de segurança (distância que separa a bola da rede no momento em que estas se cruzam), este poderá aumentar a altura da rede (manipulação do constrangimento de tarefa), o que levará a que o jogador explore novas soluções motoras (específicas a esse mesmo executante) de forma a conseguir atingir o objetivo (Araújo \& Carvalho, 2007).

A abordagem centrada nos constrangimentos (Davids e col., 2008) defende que, para se compreender a aprendizagem e desenvolvimento de habilidades desportivas, é necessário utilizar modelos dinâmicos e não-lineares de aprendizagem desportiva (Chow e col., 
2006; Chow e col., 2007). Para que a aprendizagem possa decorrer deste modo, necessita ser enquadrada por uma pedagogia que atenda a essas mesmas características.

\section{Pedagogia não-linear}

A pedagogia não-linear pode ser expressa através da manipulação de constrangimentos chave de forma a canalizar a emergência de comportamentos funcionais, na forma de padrões de ação (Chow e col., 2006; Chow e col., 2007). Para que tal seja possível, a pedagogia não-linear oferece alguns pressupostos:

i) Valorização do papel que a interação entre os vários constrangimentos desempenha, pois é da interação que emergem, de modo não-linear, novos estados de organização. Ou seja, a pedagogia não-linear não contempla um modelo ideal de execução de uma determinada ação técnica, o que se deve ao carácter dinâmico da interação entre constrangimentos - do indivíduo, do ambiente e da tarefa (Chow e col., 2006; Chow e col., 2007). Isto é, cada indivíduo tem características físicas e psicológicas diferentes, tal como o ambiente que rodeia a performance (público, temperatura, humidade, etc.) e a tarefa a desempenhar (set point, bola jogada pelo adversário, etc.). O que significa que a interação entre constrangimentos poderá não originar a emergência do mesmo comportamento em diferentes indivíduos, ou até no mesmo indivíduo em diferentes contextos de performance. Chow e colegas (2006) mostraram que, no desempenho de uma determinada ação técnica, os desportistas de elite têm padrões de comportamento caracterizados por pequenas variações, como forma de adaptação às mudanças contínuas dos constrangimentos que envolvem a performance. 
ii) O desenho de uma determinada tarefa de treino deve contemplar a representatividade da competição, pois os constrangimentos de tarefa que irão interagir no treino não devem ser diferentes daqueles que existem na competição (Araújo \& Carvalho, 2007; Chow e col., 2006; Chow e col., 2007; Davids e col., 2012). Um exemplo de baixa representatividade é a utilização de máquinas de projeção de bolas para treinar a resposta ao serviço, uma vez que no contexto de treino o jogador não tem disponíveis as ações do adversário (lançamento da bola; colocação dos pés; pega da raquete; etc.) como fontes de informação para regular a sua ação. Naturalmente, devido às questões de representatividade acima referidas, a pedagogia não-linear incentiva a utilização de exercícios que tenham um objetivo tático que envolva a execução da tarefa motora pretendida, em detrimento da utilização de exercícios puramente técnicos ou de métodos que valorizem a decomposição dos gestos técnicos.

iii) A pedagogia não-linear promove a prática exploratória (Chow e col., 2006; Chow e col., 2007), em detrimento da prática prescritiva. Isto implica que, no treino, em vez de o treinador prescrever as ações a desempenhar para se atingir um determinado objetivo, este deve criar as condições necessárias para que o executante encontre as soluções motoras que lhe permitam atingir o objetivo e que melhor se adaptem às suas características. Esta prática exploratória promove variabilidade funcional através da experimentação de diferentes possibilidades de ação que cada executante procura ativamente nos exercícios propostos pelo treinador. A exposição dos jogadores a este tipo de exercícios promove a variabilidade das soluções técnicas embutidas na tática do jogo. Desta forma, o procedimento tradicional de, antes 
da execução de um exercício, prescrever soluções técnicas consideradas ótimas (tendo por base um modelo ideal de performance), é substituído pela apresentação de um problema tático a resolver e pela exposição dos jogadores a cenários que possibilitem que cada um resolva os problemas táticos propostos, de acordo com as suas capacidades. Neste contexto tático apresentado, a manipulação sucessiva de constrangimentos canaliza o jogador a atingir o objetivo, ao mesmo tempo que desenvolve as suas capacidades. Assim, a gestão da frequência e conteúdo da informação de retorno aumentada que é fornecida aos jogadores, antes e durante a execução da tarefa em causa, também deve ser alvo de análise (Chow e col., 2013).

Numa prática tradicional, o treinador, antes e durante a execução do exercício, fornece ao jogador, de forma frequente, informações sobre as componentes críticas do movimento a executar (tendo sempre como referência um modelo ideal de execução), fazendo com que o jogador dirija a sua atenção para fatores internos, centrando-se na forma como executa as suas ações. Por outro lado, numa prática de pedagogia não-linear, o treinador apresenta o exercício como um desafio e, durante o processo de exploração, vai fornecendo informação ao jogador sobre o modo como as suas ações permitem a aproximação ou o afastamento do objetivo proposto. $\mathrm{O}$ foco de atenção passa assim a ser mais externo, dirigido para a interação com o contexto e para os resultados das suas ações e não para os processos das mesmas. Nas técnicas de prática exploratória é também habitual existir, a meio do exercício, uma conversa guiada pelo treinador em que este possibilita aos executantes a discussão de diferentes formas de cumprir o objetivo definido - tático ou técnico (Chow e col., 2007). A conversa guiada ajuda a que os praticantes 
aumentem a sua sensibilidade a outras fontes de informação relevante que lhes permitam, posteriormente, agir de modo direcionado ao mesmo objetivo.

iv) $\mathrm{Na}$ pedagogia não-linear o ensino deve valorizar a compreensão tática do jogo em causa, sendo que a técnica é encarada como um conjunto de ferramentas utilizadas para resolver problemas táticos impostos pelo jogo (Chow e col., 2007). Por isso mesmo, segundo esta perspetiva pedagógica, o ensino não deve sobrevalorizar as componentes críticas de um determinado movimento, devendo antes realçar qual o objetivo tático que esse mesmo movimento pretende alcançar. No entanto, o nível técnico funciona como um importante constrangimento, que tem uma grande influência na capacidade tática de um jogador (Chow e col., 2006; Chow e col., 2007), querendo isto dizer que também é importante a introdução e valorização de conteúdos técnicos no treino. Além disso, logo que possível, o treino de ações técnicas deve ser enquadrado em contextos táticos que simulem as condições do jogo.

\section{Abordagem tradicional vs abordagem baseada em constrangimentos (ABC)}

Para uma melhor compreensão das implicações que cada uma destas abordagens (Abordagem tradicional vs. ABC) representa para o treino, passamos a apresentar um exemplo prático onde é identificada uma situação no jogo que necessita ser melhorada e a respetiva prescrição de treino, de acordo com uma abordagem tradicional e uma abordagem baseada na manipulação dos constrangimentos. A Tabela 1 resume as principais diferenças metodológicas entre estas duas abordagens. 
Tabela 1. Resumo das principais diferenças metodológicas entre a abordagem tradicional e a $\mathrm{ABC}$

\begin{tabular}{|c|c|c|}
\hline & Abordagem tradicional & $\mathrm{ABC}$ \\
\hline Procedimentos & $\begin{array}{l}\text { - Identificação dos desvios } \\
\text { existentes em relação ao modelo } \\
\text { ideal de execução da técnica em } \\
\text { causa (erros); } \\
\text { - Utilização de ferramentas, } \\
\text { como o vídeo, para possibilitar a } \\
\text { comparação da performance do } \\
\text { aluno com a de um modelo ideal; } \\
\text { - Identificação das causas do erro } \\
\text { - Correção dos erros. }\end{array}$ & $\begin{array}{l}\text { - Identificação do problema num } \\
\text { contexto tático; } \\
\text { - Avaliação dos constrangimentos } \\
\text { chave (indivíduo; tarefa; } \\
\text { ambiente) que interagem nessa } \\
\text { situação; } \\
\text { - Seleção e manipulação } \\
\text { planeada dos constrangimentos } \\
\text { considerados chave para a } \\
\text { emergência do comportamento } \\
\text { pretendido. }\end{array}$ \\
\hline $\begin{array}{l}\text { Desenho do } \\
\text { treino }\end{array}$ & $\begin{array}{l}\text { - Treino centrado nas } \\
\text { componentes críticas envolvidas } \\
\text { na execução do movimento } \\
\text { pretendido; } \\
\text { - Preocupação com o volume de } \\
\text { treino e valorização da repetição; } \\
\text { - Utilização de exercícios } \\
\text { fechados, faseados e analíticos } \\
\text { (decomposição da técnica em } \\
\text { fases) para que o jogador possa } \\
\text { focar melhor a sua atenção a } \\
\text { cada uma das componentes de } \\
\text { execução. }\end{array}$ & $\begin{array}{l}\text { - Treino essencialmente centrado } \\
\text { no aluno e na sua relação com o } \\
\text { contexto; } \\
\text { - Preocupação com a } \\
\text { representatividade competitiva } \\
\text { das tarefas propostas; } \\
\text { - Valorização de ações dirigidas } \\
\text { para objetivos definidos; } \\
\text { - Exploração individual das } \\
\text { soluções (ações técnicas e } \\
\text { táticas) que permitem atingir os } \\
\text { objetivos. }\end{array}$ \\
\hline $\begin{array}{l}\text { Utilização da } \\
\text { informação } \\
\text { de retorno }\end{array}$ & $\begin{array}{l}\text { - Elevado fornecimento de } \\
\text { informação de retorno aumentada } \\
\text { (IRA); } \\
\text { - Utilização da IRA de forma } \\
\text { prescritiva, com o jogador } \\
\text { a aceitar passivamente a } \\
\text { informação, antes e durante a } \\
\text { execução; } \\
\text { - Utilização da IRA como } \\
\text { ferramenta para análise da } \\
\text { performance após a ação (ex. } \\
\text { comparação da execução filmada } \\
\text { com a de um modelo ideal de } \\
\text { execução). }\end{array}$ & $\begin{array}{l}\text { - Volume moderado de } \\
\text { fornecimento de IRA; } \\
\text { - Utilização de métodos } \\
\text { interrogativos, como forma de } \\
\text { incentivar o jogador a explorar } \\
\text { as várias possibilidades de } \\
\text { movimento que o contexto } \\
\text { oferece; } \\
\text { - Fornecimento de IRA na forma } \\
\text { de desafio à exploração da } \\
\text { solução, através de métodos } \\
\text { interrogativos que estimulam } \\
\text { a identificação e avaliação das } \\
\text { decisões tomadas e de novas } \\
\text { formas de agir. }\end{array}$ \\
\hline
\end{tabular}

Consideremos o seguinte exemplo: o treinador diagnostica que, no jogo, o jogador fica muitas vezes em desvantagem no ponto, porque joga frequentemente bolas com pouca profundidade, o que permite ao adversário entrar mais no campo e a partir daí ter um 
maior domínio sobre o ponto. A margem de segurança da bola face à rede (distância que separa a bola da rede quando estas se cruzam) é muito reduzida devido ao facto de o jogador utilizar pouco a ação dos membros inferiores e bater a bola muito à custa da rotação do tronco e do braço (finalização muito para o lado com o cotovelo baixo).

Na Figura 1 pode ser visto um exemplo de treino que pretende responder ao problema identificado através da utilização de uma abordagem tradicional.

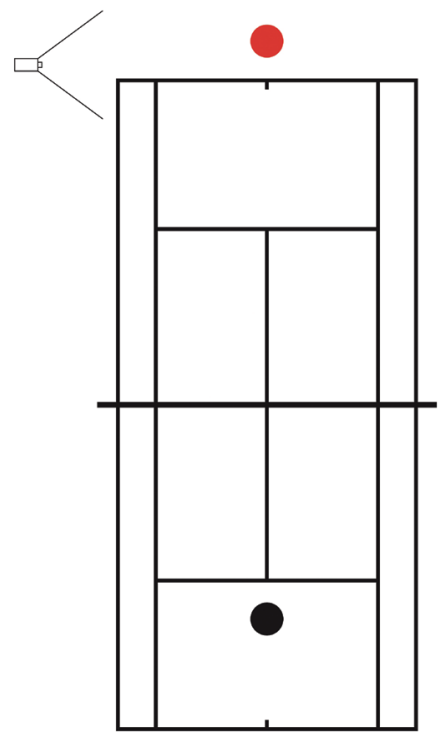

- O treinador define o número de séries e de repetições por série (ex. 6 séries com 10 repetições por série) e prescreve as componentes críticas fundamentais que pretende que o jogador execute para corrigir o movimento em causa (e.g., coloca-te mais por trás da bola, utiliza mais as pernas e a força de reação do solo, acompanha mais a trajetória da bola no follow through, acaba o movimento com o cotovelo mais alto).

- A bola é fornecida ao jogador pelo treinador (auxiliando-se com um "cesto" contendo um elevado número de bolas)

- Durante a execução do exercício o treinador vai fornecendo informação de retorno aumentada relativamente a quanto o jogador se está a afastar ou aproximar das componentes críticas prescritas.

- Colocação de uma câmara de vídeo apontada de forma a conseguir registar as ações técnicas do jogador, para posterior comparação com um modelo ideal de execução.

Legenda: - Jogador; - Treinador; $\square$ - Câmara de filmar.

Figura 1. Exemplo de exercício que se rege por uma abordagem tradicional

Nas Figuras 2 e 3 é possível verificar a resolução do mesmo problema tendo em conta a utilização da ABC (Araújo \& Carvalho, 2007). 


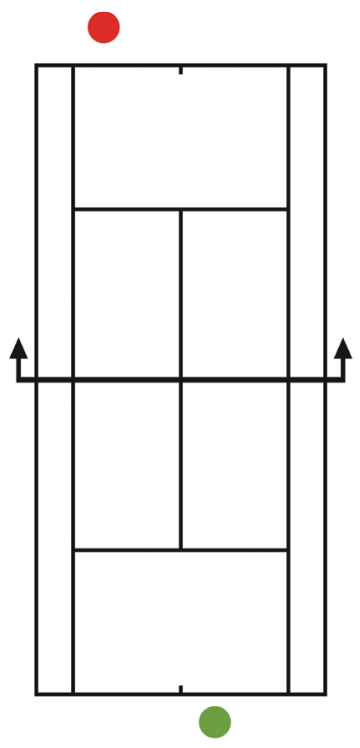

- O treinador identifica e manipula um constrangimento chave de tarefa (aumento da altura da rede).

- O exercício é apresentado na forma de disputa de pontos (e.g., jogar um set), colocando em prática todas as regras que existem em competição (excetuando o aumento da altura da rede).

- O treinador utiliza métodos interrogativos para que o(s) aluno(s) possa(m) avaliar o seu desempenho sobre o reconhecimento e aproveitamento das oportunidades

Legenda: - Jogador; - Adversário; $\uparrow$ - Aumento da altura da rede em 40 centímetros.

Figura 2. Exemplo 1 de exercício de acordo com a ABC

Na Figura 3 pode ser visto um exemplo diferente de exercício que pretende responder ao problema identificado, através da manipulação de outro constrangimento para promover a exploração da ação que permite atingir o objetivo visado.

Se os jogadores, no decorrer dos exercícios, para cumprirem os objetivos, adotarem estratégias que de alguma forma se afastem do comportamento esperado, o treinador poderá combinar estes dois constrangimentos (altura da rede e profundidade da bola) ou incluir outros que permitam a exploração de soluções no sentido pretendido. Por exemplo, se os jogadores estiverem a aumentar a profundidade da bola essencialmente através da altura da trajetória da bola, poderá ser colocada uma banda que limite a altura máxima a que a bola deverá cruzar a rede. 


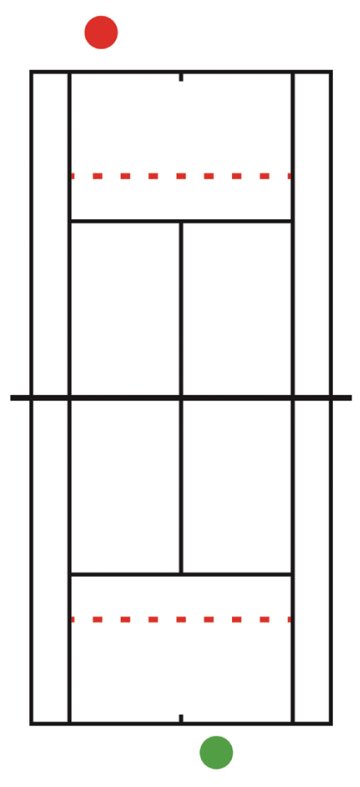

- O treinador identifica e manipula um constrangimento chave de tarefa (profundidade da colocação da bola)

- O exercício é apresentado na forma de disputa de pontos (e.g., jogar um set), colocando em prática todas as regras que existem em competição (excetuando a regra de que, excluindo o serviço, os jogadores só podem jogar para depois do tracejado, caso contrário a bola é considerada fora).

- O treinador utiliza métodos interrogativos para que $\mathrm{o}(\mathrm{s})$ aluno(s) possa(m) avaliar o seu desempenho sobre o reconhecimento e aproveitamento das oportunidades de acção que o contexto oferece.

Legenda: - Jogador; - Adversário; - Marcadores que traçam uma linha de profundidade.

Figura 3. Exemplo 2 de exercício que se rege pela $A B C$

\section{Conclusão}

Com o estudo e compreensão dos processos de aprendizagem desportiva dominados pela corrente clássica cognitivista, os modelos de treino têm assentado na redução da incerteza e na internalização dos processos de tomada de decisão. Segundo este paradigma, a metodologia de treino assume características como: i) Exercícios centrados na execução de habilidades motoras que tendam a isolar as ações do contexto competitivo onde ocorrem; ii) Treinos altamente estruturados, principalmente centrados na técnica e com uma lista de habilidades motoras ensinadas sequencialmente; iii) Utilização de métodos de decomposição de tarefa; iv) Sobrevalorização do papel 
da repetição e do volume de prática, como forma de aproximar o gesto técnico ao de um modelo considerado ideal e de fortalecer as representações mentais; v) Utilização da demonstração, instrução e informação de retorno como forma de prescrever ações a serem executadas.

Este tipo de métodos, apesar de desenvolverem uma elevada estabilidade técnica na execução de determinados movimentos desportivos, acabam por trazer aos jogadores pouca capacidade de tomada de decisão, menor capacidade de adaptação ao meio que envolve a performance e poucas oportunidades para que o jogador encontre as decisões e ações que melhor se adaptem às suas características.

No entanto, a variabilidade e a incerteza são características intrínsecas dos jogos desportivos, devido à constante interação entre os constrangimentos do indivíduo e do ambiente. Dessa forma, é necessário estudar a aprendizagem de habilidades desportivas através de princípios teóricos e metodológicos que contemplem os constrangimentos impostos pela singularidade da carga genética de cada jogador e a interação destes com os constrangimentos ambientais em que se realiza cada modalidade desportiva. A abordagem baseada nos constrangimentos (ABC) utiliza ferramentas e conceitos dos sistemas dinâmicos e valoriza a interação entre os constrangimentos do indivíduo, da tarefa e do ambiente. A ABC assenta na convicção de que é a partir desta interação que emerge o comportamento desportivo intencional, a partir de processos de autorganização. Segundo esta abordagem, a procura de eficácia assenta na exploração da variabilidade de soluções motoras como uma forma de promover a adaptação às características dinâmicas dos constrangimentos existentes em competição. $\mathrm{Na} \mathrm{ABC}$, o treino deve expor o jogador às fontes de informação que existem na competição desportiva e que são consideradas relevantes para a realização da tarefa, para que este consiga afinar a sua perceção às mesmas. Assim, a ABC considera que a manipulação de constrangimentos chave do indivíduo, 
do ambiente e da tarefa é uma ferramenta fundamental para fazer surgir o comportamento desportivo dirigido a um objetivo. Para que a aprendizagem evolua desta forma, deve ser orientada por uma pedagogia não-linear.

A pedagogia não-linear oferece alguns pressupostos que possibilitam que a manipulação de constrangimentos chave canalize a emergência de comportamento funcional, tais como: i) o treino não se basear em modelos considerados "ideais" de desempenho, devido ao carácter único e dinâmico que cada categoria de constrangimentos (indivíduo, tarefa e ambiente) representa; ii) os exercícios de treino devem ser representativos da competição, para que o indivíduo aprenda a interagir com os constrangimentos de tarefa que existem na competição; iii) a prática exploratória deve ser valorizada em detrimento da prática prescritiva, de forma a promover a variabilidade funcional através da experimentação de diferentes possibilidades de ação; iv) a informação de retorno aumentada deve ser dirigida para um foco externo, guiando assim a atenção do jogador para os resultados das suas ações e não tanto para a forma como são realizadas; v) valorização da tática do jogo como motor do processo de aprendizagem; vi) a técnica deve ser encarada como um conjunto de ferramentas utilizadas para resolver problemas táticos impostos pelo jogo.

Tal como demonstram os exemplos práticos apresentados no ténis, as diferenças metodológicas entre a abordagem tradicional e a ABC são significativas e devem ser alvo de atenção no planeamento do treino desportivo.

\section{Bibliografia}

Araújo, D., \& Carvalho, J. (2007). A tomada de decisão no ténis. In P.P. Correia, C. Coutinho (Eds.), Investigação e Ténis (pp. 85-102). Cruz Quebrada: FMH Publicações. 
Carvalho, J., Araújo, D., González, L.G., \& Iglesias, D. (2011). El entrenamiento de la toma de decisiones en el ténis: qué fundamentos cientificos se pueden aplicar en los programas de entrenamiento? Revista de Psicologia del Deporte, 20, 767 783.

Chow, J.Y., Davids, K., Button, C., Shuttleworth, R., Renshaw, I., \& Araújo, D. (2006). Nonlinear pedagogy: A constrain-led framework for understanding emergence of game play and movement skills. Nonlinear Dynamics, Psychology, and Life Sciences, 10, 71-103.

Chow, J.Y., Davids, K., Button, C., Shuttleworth, R., Renshaw, I., \& Araújo, D. (2007). The role of nonlinear pedagogy in physical education. Review of Educational Research, 77, 251-278.

Chow, J.Y., Koh, M., Davids, K., Button, C., \& Rein, R. (2013). Effects of different instructional constrains on task performance and emergence of coordination in children. European Journal of Sport Sciences, 14, 224-232.

Davids, K., Glazier, P., Araújo, D., \& Barlett, R. (2003). Movement systems as dynamical systems. The functional role of variability and its implications for sports medicine. Sports Medicine, 33, 245-260.

Davids, K., Renshaw, I., Pinder, R., Araújo, D., \& Vilar, L. (2012). Principles of motor learning in ecological dynamics. A comment on functions of learning and the acquisition of motor skills (with reference to sport). The Open Sport Sciences Journal, 5, 113-117.

Davids, K., Araújo, D., Correia, V., \& Vilar, L. (2013). How small-sided and conditioned games enhance acquisition of movement and decision-making skills. Exercise and Sports Sciences Reviews, 41, 154-161.

Newell, K.M. (1985). Coordination, control and skill. In D. Goodman, I. Franks, R.B. Wilberg (Eds.), Differing Perspectives in Motor Learning, Memory and Control (pp.295-317). Champaign, IL: University of Illinois.

Newell, K.M. (1986). Constrains on the development of coordination. In M.G. Wade, H.T.A. Whiting (Eds.), Motor Development in Children. Aspects of Coordination and Control (pp. 341-360). Dordrecht: Martinus Nijhoff.

Newell, K.M. (1996). Change in movement and skill: Learning, retention and transfer. In M.L. Latash, M.T. Turvey (Eds.), Dexterity and its Development (pp. 393-430). Mahwah, NJ: Lawrence Erlbaum.

Passos, P., Batalau, R., \& Gonçalves, P. (2006). Comparação entre as abordagens ecológica e cognitivista para o treino da tomada de decisão no ténis e no rugby. Revista Portuguesa de Ciências do Desporto, 6, 305-317.

Seifert, L., Button, C., \& Davids, K. (2013). Key properties of expert movement systems in sport. Sports Medicine, 43, 167-178. 